\title{
Caracterización del componente pragmático del lenguaje en educandos con retardo en el desarrollo psíquico
}

Fecha de recepción : 10 de octubre de 2018 • Fecha de aceptación: 1 de noviembre de 2018 • Fecha de publicación: 7 de enero de 2019

PhD. Milagros de la Caridad Sánchez Herrera Universidad de Ciego de Ávila Máximo Gómez Báez (UNICA), Cuba milagrossh@sma.unica.cu

PhD. Adria Leiva Pérez Universidad de Ciego de Ávila Máximo Gómez Báez (UNICA), Cuba adrialp@sma.unica.cu

Iracema Díaz Paz Universidad de Ciego de Ávila Máximo Gómez Báez (UNICA), Cuba iracemadp@sma.unica.cu

\section{Resumen}

El trabajo aborda las regularidades del desarrollo del lenguaje en educandos con retardo en el desarrollo psíquico, obtenidas en las investigaciones del proyecto "La atención educativa integral a niños, adolescentes y jóvenes con necesidades educativas especiales" y en la tesis de doctorado de la Ph. D. Milagros de la Caridad Sánchez Herrera, lo que permitió realizar precisiones a las caracterizaciones precedentes y aportar la caracterización del componente pragmático. Se ofrecen, además, recomendaciones para la exploración, así como acciones, ejercicios y recursos didácticos para el desarrollo del lenguaje. En el proceso investigativo se emplearon los siguientes métodos y técnicas: analítico-sintético, inductivo-deductivo, histórico-lógico, análisis documental, exploración logopédica, encuesta, observación y entrevista. 


\begin{abstract}
This paper addresses the regularities of language development in students with psychic development delay, obtained in the research project "La atención educativa integral a niños, adolescentes y jóvenes con necesidades educativas especiales" ("Comprehensive Educational Care for Children, Adolescents and Young People with Special Educational Needs") and in the PhD thesis of Milagros de la Caridad Sánchez Herrera, which allowed to make precisions to the previous characterizations and to contribute the characterization of the pragmatic component. In addition, recommendations for exploration are offered, as well as actions, exercises and didactic resources for language development. In the research process, the following methods and techniques were used: analytical-synthetic, inductive-deductive, historical-logical, documentary analysis, logopedic exploration, survey, observation and interview.
\end{abstract}

Keywords: Language, pragmatic component, psychic development delay. 


\section{Introducción}

Los resultados del proyecto de investigación "La atención educativa integral a niños, adolescentes y jóvenes con necesidades educativas especiales" de la provincia Ciego de Ávila, permitieron identificar deficiencias en la atención individualizada al desarrollo del lenguaje de los educandos con retardo en el desarrollo psíquico (RDP) en el proceso de enseñanza-aprendizaje (PEA), las que son más evidentes en el segundo grado, donde llegan sin vencer los objetivos del primero, y con marcadas dificultades en el lenguaje.

La indagación empírica permitió determinar que existen limitaciones relacionadas con la descripción insuficiente de los componentes estructurales del lenguaje en las exploraciones logopédicas que aparecen en los expedientes psicopedagógicos de los educandos con RDP de segundo grado, aun cuando de esta caracterización depende el posterior trabajo para el desarrollo del lenguaje y su atención individualizada.

Las regularidades del lenguaje de los educandos con RDP es motivo de análisis por diferentes investigadores. Dentro de estos, Vlasova y Pevzner (1981); Torres, Domishkievich y Herrera (1990); Vlasova, Lubovski y Tsipina (1992), y Castellanos et al. (2013). La primera caracterización del lenguaje de los educandos con RDP en Cuba la ofrecen Torres et al. (1990), quienes exponen que en estos educandos aparecen afectados los tres componentes estructurales del lenguaje: el fonético-fonológico, el léxico-semántico y el gramatical; aunque no todos presentan el mismo grado de dificultad en cada componente.

Castellanos et al. (2013), tomando como referente a Torres et al. (1990), expresan que en estos educandos aparece, en el aspecto fonético, la prolongación de inadecuaciones de la pronunciación en palabras extensas, complejas y desconocidas, relacionadas con sonidos de similitud sonora. En el semántico, se afecta el vocabulario de contenido más abstracto y tienden a la percepción fragmentada de oraciones, lo que entorpece su comprensión. Así mismo, se les dificulta la construcción de enunciados verbales coherentes, sus respuestas son cortas y poseen un carácter situacional. En el gramatical, presentan errores de logicidad de la expresión y de la sintaxis, sobre todo en las tareas verbales de mayor complejidad. Todo esto origina dificultades en el aprendizaje; sin embargo, apuntan que con la ayuda pedagógica adecuada se puede lograr el éxito.

El estudio teórico permitió determinar que en las caracterizaciones de las regularidades del lenguaje de los educandos con RDP, hechas por los autores citados, se exponen las dificultades descritas en los componentes estructurales: fónico-fonológico, léxico-semántico y gramatical; sin embargo, no se describe el componente pragmático.

Al respecto, Álvarez et al. (2007) y Fernández, Pons, Carreras y Rodríguez (2013), enuncian que el componente pragmático del lenguaje se encuentra afectado en algunos trastornos de la comunicación y el lenguaje; pero no explican suficientemente cómo diagnosticarlo y desarrollarlo, ni lo abordan en específico en educandos con RDP. Autores como Acuña y Sentis (2004), Álvarez et al. (2007) y Fernández y Huepp (2014), lo consideran como el conjunto de reglas o factores extralingüísticos que hacen posible el empleo adecuado de enunciados en las situaciones 
concretas en las que tiene lugar el intercambio conversacional entre las personas, adecuado a la situación y al contexto de comunicación, aceptable para el receptor y por tanto eficaz.

Las características específicas en el componente pragmático, al igual que las descritas en los restantes componentes, repercuten en el aprendizaje y en el desarrollo integral de la personalidad. Como premisa para las caracterizaciones psicopedagógicas y el diseño de las estrategias de atención individualizada (como se establece en el enfoque de atención integral a las NEE necesidades educativas especiales - , el cual concede primordial importancia al proceso de evaluación y caracterización para ofrecer la atención en correspondencia con las particularidades individuales), resulta necesario profundizar en el estudio de las regularidades que caracterizan el desarrollo del lenguaje de los educandos con RDP.

Para el desarrollo de la investigación se seleccionó una población compuesta por los educandos con RDP de segundo grado de seis escuelas de la provincia Ciego de Ávila, por cuatro cursos consecutivos: 115 en el curso 2012-2013, 95 en el curso 2013-2014, 89 en el curso 2014-2015 y 60 en el curso 2015-2016.

Se emplearon diferentes métodos y técnicas tanto del nivel teórico como del empírico.

- Nivel teórico: Se empleó el método analítico-sintético para el análisis de los fundamentos teóricos que sirven de base al desarrollo del lenguaje en educandos con RDP, así como para el procesamiento de los datos empíricos y para arribar a conclusiones. Así mismo, se empleó el método inductivo-deductivo para establecer generalizaciones y llegar a conclusiones en relación con las concepciones actuales que fundamentan el desarrollo del lenguaje, a partir del criterio de diferentes autores. Y se empleó el método histórico-lógico en la sistematización de las caracterizaciones del lenguaje de los educandos con RDP.

- Nivel empírico: Se empleó el análisis documental para la revisión de los expedientes psicopedagógicos, con el objetivo de analizar la caracterización del lenguaje de los educandos con RDP. Se empleó, además, la exploración logopédica para caracterizar el lenguaje de los educandos de segundo grado con RDP. Y se aplicaron encuestas a logopedas para corroborar el grado de aceptación de las regularidades detectadas.

Se diseñaron, aplicaron y tabularon los siguientes instrumentos: guía para el análisis de documentos, modelo de exploración logopédica, entrevista a logopedas, encuesta a maestros y guía de observación a clases. Estos instrumentos fueron sometidos a pilotaje, el cual corroboró su factibilidad para obtener la información deseada en cada caso.

\section{Desarrollo}

Según Fernández et al. (2013) el lenguaje constituye un indicador importante en la evaluación de los procesos cognitivos; la manifestación de los progresos que el niño alcanza en este aspecto indica generalmente un adecuado comportamiento de los procesos neuropsicológicos en los que descansa la producción y comprensión de los enunciados verbales. Cualquier retraso significativo que manifiesten los niños en el desarrollo de los medios o componentes del lenguaje (fonológico, 
léxico semántico, morfosintáctico) y en la conducta comunicativa que asumen en los diferentes contextos, revela las posibles complicaciones que pudieran presentar en su desarrollo.

En cuanto a la descripción de los componentes estructurales del lenguaje, Martínez (2004) plantea que el componente fonético-fonológico abarca el conjunto de sonidos del idioma y sus modelos o tipos ideales, los fonemas, los cuales se desarrollan mediante la percepción e imitación de los sonidos y sus combinaciones en las palabras, y de manera paulatina se perfecciona su articulación y diferenciación. Por su parte, el componente léxico-semántico abarca el vocabulario, la comprensión y el uso de la lengua (palabras) en dependencia de su significado. Y el gramatical comprende la morfología (leyes de transformación de las palabras) y la sintaxis (combinación de palabras dentro de la oración). Este componente surge de manera más tardía que los anteriores y su alteración puede implicar limitaciones en las otras.

En la literatura más actualizada, diferentes investigadores, entre ellos Frías (2001), Monfort (2004), Acuña y Sentis (2004), Álvarez et al. (2007) y Fernández et al. (2013), se refieren, además de a los tres componentes antes explicados, al componente competencia o nivel pragmático del lenguaje.

Se asume el criterio de que el lenguaje oral propone un código comunicativo entre los participantes en el intercambio comunicativo y contiene en su textura normas de uso, modalidades de acceso al significado y una serie de indicaciones que posibilitan que el enunciado sea adecuado a la situación, al contexto de comunicación, común al receptor y el emisor, y por tanto eficaz. "La pragmática puede definirse como el uso social del lenguaje, es decir, la capacidad de entender las intenciones de los demás cuando hablan y de expresar las propias, de una forma eficaz y con un manejo del código apropiado al contexto" (Monfort, 2004, p.85).

Según Álvarez et al. (2007), el lenguaje extraverbal tiene diferentes funciones, tales como facilitar el lenguaje verbal, añadir el componente emotivo al racional, participar en la intencionalidad de la comunicación, así como mantener el equilibrio interpersonal y social mediante gestos, miradas, posturas, entonación de la voz y reacciones afectivas. Las intenciones comunicativas, llamadas también funciones pragmáticas, se van complejizando a medida que crece el niño; en orden cronológico, se desarrollan las funciones instrumental, reguladora e interactiva del lenguaje.

A partir del estudio teórico realizado en esta investigación se concreta la definición y estructura del componente pragmático del lenguaje. Y así tenemos que este componente se refiere al conjunto de reglas o factores extralingüísticos aceptables para emisor y receptor, que posibilitan entender las intenciones de los demás cuando hablan y expresar las propias en el intercambio conversacional, acorde con la situación y el contexto de comunicación, y por tanto eficaz. Además, solo pueden interpretarse en una determinada situación comunicativa y condiciona acciones por los interlocutores.

El componente pragmático está integrado por la interacción verbal, la comunicación no verbal y la intención comunicativa, los cuales determinan su uso funcional. La interacción verbal se refiere al inicio y toma de turnos en la conversación, a la formulación de preguntas y demandas, así como a las respuestas a preguntas y la coherencia del discurso ajustado a cambios de la interacción. La comunicación no verbal incluye el uso de gestos, miradas, sonrisas, movimientos corporales, 
así como las reacciones afectivas (enojo, risa, llanto, etc.) de los interlocutores. La intención comunicativa, por su parte, contiene indicadores verbales, como dirección de la mirada, cambios en la entonación e intensidad de la voz y naturaleza del acto precedente y subsecuente.

Para los casos en que se altere el componente pragmático del lenguaje Álvarez et al. (2007) ofrecen una rehabilitación del lenguaje extraverbal y una rehabilitación pragmática.

Para la rehabilitación del lenguaje extraverbal sugieren:

Captar la importancia de los movimientos corporales, faciales y vocales de la comunicación, estimular el desarrollo de las expresiones corporales y entonar los diferentes enunciados verbales apoyándose en movimientos corporales. Actividades: tareas de expresión facial, imitación de movimientos de animales, gestos y sonidos de diferentes profesiones, entonación de diferentes estructuras lingüísticas (admiración, interrogación), preguntas y respuestas diferentes ante un mismo hecho o cosa y dramatizaciones, relatos. (p.36)

La rehabilitación pragmática tiene los siguientes objetivos:

Usar el lenguaje funcionalmente, utilizar el lenguaje en sus diversas funciones, emplear el lenguaje verbal y extraverbal adecuadamente y fortalecer la vertiente comunicativa del lenguaje. Actividades: tareas de identificación/emisión de órdenes, de identificación/ emisión de mensajes, de reconocimiento/expresión de sentimientos, deseos, opiniones, etc., descripción de hechos, personas, acontecimientos, etc., de suposición de narración y conclusiones ante hechos determinados y tareas en que los niños deban demandar información, solicitar la atención de otro, ruegos, juegos de roles. (p.37)

Las autoras de la presente investigación reconocen los componentes estructurales del lenguaje: fonético-fonológico, léxico-semántico, gramatical y pragmático; y consideran que lo expuesto anteriormente acerca del componente pragmático posibilita su descripción y comprensión desde la teoría a fin de detectar los síntomas en casos de alteraciones, para lo que, además, se deben conocer las regularidades del lenguaje de estos educandos descritas en las caracterizaciones precedentes.

Las caracterizaciones del lenguaje de los educandos con RDP de Vlasova y Pevzner (1981), Torres et al. (1990), Vlasova et al. (1992) y Castellanos et al. (2013) constituyen significativos aportes, que marcan pautas en este tema. Todos coinciden en que estos educandos presentan alteraciones, de mayor o menor grado, en los componentes fónico-fonológico, léxico-semántico y gramatical, así como en la repercusión que tienen estas alteraciones en el aprendizaje de la lectoescritura. No obstante, en correspondencia con la teoría más avanzada en este campo, se requiere profundizar en las características que, a manera de regularidades, presentan en el componente pragmático del lenguaje, que se encuentra también afectado, lo cual, junto con los componentes descritos por los autores precedentes, justifica la necesidad de la atención individualizada para su desarrollo. 


\section{Caracterización del lenguaje de los educandos con retardo en el desarrollo psíquico}

El componente fonético-fonológico se afecta por los errores en la pronunciación de sonidos similares con una influencia directa de la insuficiencia en la percepción fonemática y por la inmadurez articulatoria relacionada con la regulación psíquica de los movimientos, sobre todo en palabras extensas (tres o más sílabas), complejas (varias sílabas y alguna directa doble, por la unión de dos vocales o dos consonantes y en las sílabas inversas), desconocidas y de contenido abstracto. Ejemplos: refrigerador, destornillador, escaparate, escopetas, trapeador, espejuelos, serpiente, constructor, herramientas, ladrillo, bueno, huevos, abuela, albañil y ñandú.

El componente léxico-semántico, con respecto a la edad y al grado, es reducido en cuanto a volumen y significado, tanto en el vocabulario activo como en el pasivo. Tiene un carácter concreto-situacional. Las limitaciones son marcadas en palabras complejas y de contenido abstracto, las que son menos utilizadas en los contextos donde se desenvuelven. Presentan incoherencias lexicales, uso inexacto de algunos vocablos que, por desconocimiento de la palabra precisa y sin el razonamiento adecuado basado en sus conceptos, no se corresponden con la idea a expresar, por lo que manifiestan pobre comprensión del significado de frases y mensajes que escuchan.

Emplean pocos sinónimos, antónimos e hiperónimos. Pobre incorporación a su vocabulario activo de palabras trabajadas en las diferentes asignaturas. Pobre dominio de verbos y sustantivos, particularmente de términos que designan oficios. Presentan dificultades semánticas en ordeñar, torcer, librero, garaje, tumbona, lámpara, buró, hamaca, machetero, constructor, vago, goloso, así como en los nombres de las aves, los medios de transporte, los instrumentos musicales, las herramientas de trabajo y las frutas.

En el componente gramatical evidencian pobre desarrollo de la expresión oral, falta de espontaneidad para comunicar sus ideas, dificultades para formular las ideas sobre un tema determinado, poca coherencia en su discurso; así mismo, emplean estructuras sencillas, solo sujeto y predicado, con pocos o ningún complemento circunstancial de modo, tiempo o lugar, y utilizan pocos sustantivos, adjetivos y verbos. Redactan oraciones orales sencillas a partir de una palabra dada, una imagen visual, y en respuesta a preguntas. Tienen dificultades para la redacción oral a partir de dos palabras, en una misma oración o dos interrelacionadas. Presentan graves dificultades para la descripción; sus narraciones son cortas y según sus contextos. En el lenguaje escrito, no logran comunicar por sí solos, de forma lógica, los mensajes, ideas y emociones.

En el componente pragmático recurren a códigos coloquiales sin considerar la manera correcta de dirigirse a las personas con las que hablan. Hacen un uso indebido del nivel reproductivo en repeticiones léxicas y frases estereotipadas que aprendieron. Presentan dificultades en la intención comunicativa cuando conversan con adultos $u$ otros educandos que no tienen deficiencias intelectuales.

Se aprecia que emplean de manera excesiva gestos de impaciencia cuando se les dificulta expresarse, o de inseguridad e insatisfacción ante exigencias por encima de sus posibilidades. 
Recurren a expresiones corporales para indicar necesidad de afecto, manifestaciones de inconformidad, disgusto; por ejemplo, golpean con el pie en el piso o incluso pueden llegar a rabietas. Estas características están relacionadas con las alteraciones en el área inductora, afectada en ellos y que determina el interés por la comunicación y la motivación para expresar sus ideas.

En resumen, estos educandos manifiestan dificultades en los componentes estructurales del lenguaje (fonético-fonológico, léxico-semántico, gramatical y pragmático), por lo que requieren de una atención individualizada para su desarrollo.

Para caracterizar el lenguaje de los educandos con RDP en cada uno de sus componentes estructurales, atendiendo a potencialidades y necesidades, se recomienda explorar cada aspecto del modelo de exploración logopédica y profundizar en los que a continuación se relacionan:

Examen de la pronunciación. Se analiza la presencia de alteraciones de sonidos aislados y en las diferentes posiciones en las palabras (inicial, media y final). La forma en que se manifiestan dichas alteraciones son las siguientes: sustituciones, omisiones, distorsiones, adiciones, transposiciones o inconstancias. De detectarse alguna de estas formas en la pronunciación, la logopeda brindará atención logopédica vía directa al educando y orientará de manera sistemática el proceder correspondiente tanto a familiares como docentes. Se insiste en la interrelación sistemática maestro-logopeda para la evaluación de los logros y dificultades, así como para la reelaboración de las orientaciones.

En caso de que las alteraciones en la pronunciación no sean de las formas planteadas y estén vinculadas a inmadurez articulatoria relacionada con la regulación psíquica de los movimientos articulatorios, a palabras de difícil pronunciación por extensas, o por combinaciones de sonidos complejos, o de contenido abstracto que no dominan su significado, se reflejarán las particularidades específicas en su caracterización y se brindará atención individualizada durante la clase.

Determinación del estado del vocabulario activo y pasivo en cuanto a volumen (cantidad de palabras) y significado (nominación precisa de objetos, acciones, cualidades), con respecto a la edad y al grado, así como al empleo de sinónimos, antónimos e hiperónimos. Valoración del estado del léxico para la formación de palabras, respuestas a preguntas, adivinanzas, descripción de láminas, empleo del léxico cotidiano o de contenido más abstracto para narrar, describir o expresarse acerca de un tema determinado. Ejemplificación de las palabras donde presenten dificultades.

Precisión del componente gramatical: tipo de oraciones empleadas (sencillas o complejas, relacionadas). Uso de adjetivos, preposiciones, artículos y complementos dentro de la oración (directos o circunstanciales de modo, tiempo y lugar). La conjugación de los verbos y la concordancia entre género y número entre artículos, sustantivos, adjetivos y verbos.

Valoración del componente pragmático: correspondencia entre la intención comunicativa con lo que comunica, comprensión de las intenciones de los demás, participación por turnos en la 
conversación, formulación de preguntas y demandas, respuestas a preguntas, enunciado (manejo de un código común), cambios en la entonación, inflexiones e intensidad de la voz, empleo de conductas afectivas para expresarse (enojo, risa, llanto, etc.). La coherencia entre los medios verbales y extraverbales: función de la mirada, sonrisa, gestos faciales, mímica, movimientos de las manos y el cuerpo, el significado de la expresión en el contexto socio-cultural: subir y bajar de forma reiterada la cabeza, arrugar el entrecejo, morderse los labios, sonreír, dar la mano; indicar con gestos silencio, despedida, aprobación.

Además de otras variables relevantes para la comprensión de un enunciado o para explicar la elección de determinadas formas de expresarse en función de los factores contextuales, la situación, se analiza el lugar y el tiempo donde ocurre el discurso, el ajuste de la comunicación establecida al contexto socio-cultural y a las personas presentes, el tipo de relación entre ellas, el carácter de la información (compartida, concreta), la función que realiza (emisor o destinatario), la naturaleza del acto precedente y subsecuente.

Evaluación general del desarrollo del lenguaje alcanzado por el educando, determinar si logra enunciar sus ideas con coherencia y con sentido lógico, responder a preguntas, demostrar los conocimientos adquiridos, expresar sus sentimientos y mostrar las habilidades aprendidas para narrar, describir, conversar, entre otros.

\section{Acciones para el desarrollo del lenguaje}

En este sentido, se ofrecen orientaciones generales para elaborar la estrategia educativa en dependencia de las características, potencialidades y necesidades de cada educando. Entre ellas: recibir tratamiento logopédico vía directa para corregir o compensar el trastorno de la comunicación y el lenguaje que presenta; o recibir tratamiento logopédico vía indirecta para estimular el desarrollo de los componentes fonético-fonológico, léxico-semántico, gramatical y pragmático, así como el aprendizaje de la lecto-escritura.

Componente fonético-fonológico: debe practicar gimnasia pre-articulatoria para la pronunciación de palabras complejas o extensas y de contenido abstracto, automatizar la pronunciación correcta de palabras complejas o extensas y de contenido abstracto, y ejecutar actividades para el desarrollo de la percepción fonemática.

Componente léxico-semántico: aprender nuevos vocablos (sinónimos, antónimos e hiperónimos), incorporarlos de otras materias y actividades escolares para perfeccionar los conocimientos sobre temas variados, acceder al software "Jugando con las palabras" y emplear el diccionario para comprenderlas, dominar el significado de las palabras que conocen y no utilizan, así como de las de contenido abstracto, para su incorporación en el vocabulario activo.

Componente gramatical: practicar la concordancia entre género y número y la conjugación de verbos con ejercicios motivantes y creativos; ejercitar la redacción de oraciones a partir de imágenes visuales, palabras, completamiento de frases, entre otros, para lograr oraciones más completas; interactuar en el software educativo "Nuestro Idioma" para estimular la comprensión 
lectora y ejercitar la gramática; inscribirse en el festival de adivinanzas, trabalenguas o poesías.

Componente pragmático: participar en actividades cooperativas para propiciar relaciones afectivas positivas con los demás miembros del grupo y el docente; sentir seguridad y confianza en que puede lograr la tarea; actuar en dramatizaciones de cuentos como uno de sus personajes para aprender nuevas formas de expresión; jugar a la pantomima para expresar mediante el lenguaje corporal sentimientos, necesidades, estados de ánimo; intercambiar con sus compañeros en diferentes actividades para aprender a regular su conducta; no mostrarse impacientes e inseguros.

\section{Ejercicios para el diseño de tareas docentes individualizadas}

Los ejercicios que se proponen se deben emplear en dependencia de las características del lenguaje, las potencialidades y necesidades de cada educando. Se trabajará además de forma tal que, mientras se estimula el desarrollo de un componente, se estimulen también los restantes, como una unidad indisoluble.

Se trabajará la motricidad de los órganos activos (labios, lengua, maxilar inferior, velo del paladar), la pronunciación correcta de las palabras complejas o de contenido abstracto, las que incrementarán de manera sistemática en su vocabulario, tomándose de las diferentes asignaturas, y haciendo énfasis en la comprensión de los significados. A su vez se emplearán adjetivos, sinónimos, antónimos e hiperónimos de esos vocablos, los que se incorporarán en estructuras gramaticales coherentes, en conversaciones, descripciones y narraciones, para lo que utilizarán el lenguaje verbal y no verbal: la entonación adecuada, movimientos córporo-faciales, miradas, gestos, posturas y las reacciones afectivas, de manera que propicien la expresión oral, el intercambio y el equilibrio interpersonal y social.

Se debe lograr la motivación hacia el desarrollo del lenguaje con actividades creativas, novedosas, que estimulen motivos cognoscitivos, laborales, artísticos, entre otros. Asimismo, se debe lograr que las vivencias afectivas (afectos, emociones, sentimientos, estados de ánimo) sean agradables y propicien la comunicación con los que les rodean, y que su actividad volitiva les posibilite vencer obstáculos, reflexionar y tomar decisiones. Se estimularán sus logros por insignificantes que parezcan para originar alegría y proporcionar sensaciones y emociones positivas.

Componente fonético-fonológico. Labios: extenderlos hacia afuera en forma de tubo, simular una sonrisa forzada, moverlos hacia un lado o al otro, recogerlos hacia dentro, apretar uno contra el otro, hacerlos vibrar como el sonido de un motor. Lengua: efectuar movimientos giratorios por fuera de la boca, pasarla por el maxilar superior como un barrido, limpiar los labios con ella, tocar con la punta cuatro puntos fuera de la boca (arriba, abajo, izquierda y derecha), hacer el chasquido, tocar una u otra mejilla, limpiarlas con la lengua, tocar los dientes y las muelas, hacerla vibrar imitando la posición de repetidas IIIII, ttttt o ddddd o rrrrrr. Maxilar inferior: mover la mandíbula arriba y abajo, a un lado y a otro. Velo del paladar: simular gárgaras, pronunciar combinaciones silábicas inversas ak, ek, ik, ok, uk, imitar el jadeo.

Pronunciación de palabras cuyo significado no dominan, difíciles por extensas, o por presentar combinaciones de sonidos complejos o contenido abstracto. Se trabajarán con apoyo de medios 
visuales y de objetos reales, en la medida de las posibilidades. Se propone, si es necesario, escenificar el contenido de la palabra para su comprensión exacta. Para la corrección de su pronunciación se recomienda dividir la palabra en sílabas o en partes, de forma que el educando logre pronunciar esas partes por separado para luego integrarlas.

Componente léxico-semántico: identificar, en conjuntos, diferentes hiperónimos (personas, oficios, instrumentos musicales y de trabajo, medios de transporte, prendas de vestir, animales, plantas, flores, alimentos, etc. Relacionar columnas de oficios y los instrumentos que se utilizan en ellos. Enseñar nuevas palabras al determinar cualidades en las personas (fiel, ágil, hábil, honesto agradable), objetos (húmedo, frondoso, precioso) o fenómenos: (extenso, ardiente, apagado, submarino), entre otros.

Componente gramatical: completar oraciones con determinadas palabras para el desarrollo de la redacción; enlazar palabras o frases para el desarrollo de habilidades en la concordancia entre género y número; redactar oraciones a partir de imágenes, de una o dos palabras dadas; dos oraciones interrelacionadas a partir de palabras dadas, de imágenes; ampliar oraciones a partir de una frase dada, o de la incorporación de complementos de lugar, tiempo y modo, mediante niveles de ayuda; elaborar frases a partir de la búsqueda de preposiciones, artículos o adjetivos para sustantivos específicos; jugar a ¿Quién dice más.... sustantivos comunes, adjetivos o verbos, palabras para completar una oración o un párrafo?; narrar cuentos, anécdotas, hechos acontecidos, de su vida, históricos u otros.

Componente pragmático: manifestar sentimientos mediante las expresiones faciales; interpretar dramatizaciones donde expresen con lenguaje no verbal sus sentimientos, sin llegar a su uso exagerado; imitar movimientos de animales, gestos y sonidos que identifiquen diferentes profesiones u oficios; jugar a las pantomimas donde usen gestos, mímica para exponer ideas, jugar a interpretar emociones que representa el docente u otro compañero del grupo.

Diferenciar en una misma frase con entonación diferente, varias intenciones comunicativas, en oraciones interrogativas, afirmativas o exclamativas; preguntar y responder de diferente manera ante un mismo estímulo, hecho, fenómeno u objeto; diferenciar en una misma frase varias intenciones comunicativas, por el uso de pausas que determinen una acción o su negación; interpretar frases con diferentes intenciones comunicativas: en sentido figurado, mentiras, ironías, entre otros; identificar/emitir órdenes o mensajes en diferentes situaciones comunicativas; demandar información, solicitar la atención de las personas que le rodean; reconocer/expresar sentimientos, deseos, opiniones, ruegos.

Interpretar personajes en dramatizaciones de cuentos, anécdotas; participar en juegos de roles; describir hechos, personas, acontecimientos; narrar hechos determinados según su suposición y emitir conclusiones; narrar cuentos para aprender diferentes formas de manifestar tristeza ante un fracaso; imaginar un final diferente para un cuento y narrarlo de forma oral; narrar hechos históricos o relatos para aprender diferentes formas de manifestar disgusto ante situaciones adversas, demostrar seguridad en los éxitos y que aunque existan reveces se puede conseguir el resultado esperado. 


\section{Recursos didácticos para el desarrollo del lenguaje}

Según la clasificación que presenta Guirado (2011), la cual se valora como pertinente para la atención a las personas con NEE, dentro de las que se incluyen los educandos con RDP, los recursos didácticos se agrupan en cuatro áreas: el soporte interactivo, la intención comunicativa, su fuente de obtención y su uso en el PEA.

En esta clasificación de los recursos didácticos se destaca la influencia que ejerce el compañero del grupo u otra persona que interactúe con el educando, hasta el propio docente, siempre que este último sea mediador del aprendizaje. Presupone la utilización del conocimiento anterior y el desarrollo hacia uno nuevo. Recomienda el empleo de recursos didácticos en dependencia de las características de los interactuantes. Refiere la posibilidad de guiar el accionar cognitivo, actitudinal y vivencial. Así mismo, recomienda la gradación e individualización de las actividades. Se deduce que al utilizarlos para la atención individualizada al desarrollo del lenguaje de los educandos con RDP, estos posean potencialidades en los componentes estructurales del lenguaje y su empleo eficiente favorece su desarrollo.

Recursos didácticos para la caracterización del lenguaje de los educandos con RDP: se deben utilizar tarjetas con ilustraciones de palabras que contengan los sonidos en diferentes posiciones (inicial, media y final), objetos reales, maquetas, remedos, juguetes $u$ otros objetos que representen palabras complejas, extensas o que no sean de uso común. El vocabulario por imágenes se puede confeccionar a partir del vocabulario que recomiendan López, López y Villalón (2006). Se pueden utilizar láminas, secuencias, tarjetas de generalización y cuartos excluidos sugeridos por Cárdenas, Martín, Méndez y Prado (1979); y también textos, la pantalla perforada, juguetes sonoros, grabaciones, software, intercambio conversacional con el docente o con los compañeros del grupo durante la clase u otras actividades, etcétera.

Propuesta de recursos didácticos para la atención individualizada al desarrollo del lenguaje de los educandos con RDP: objetos reales, maquetas, modelos, remedos, pizarra, franelógrafo, componedor, láminas o tarjetas ilustradas, secuencias de láminas, fotografías, libros de textos, diccionarios, revistas, periódicos, juegos didácticos, instrumentos musicales, juguetes sonoros, ruidos de animales y del medio ambiente, grabaciones, musicales, videos, filmes, musicales, animados infantiles, software, el docente y los compañeros del grupo, formas elocutivas: conversaciones, narraciones, argumentaciones, descripciones y exposiciones; inflexiones de la voz, lenguaje corporal, mímica, gestos, pantomimas, dramatizaciones, entre otros.

Los recursos didácticos son variados y estarán en función del desarrollo del lenguaje siempre que permitan la interacción en situaciones comunicativas, que constituyan modelos del discurso con diferentes intenciones y se utilicen en dependencia del diagnóstico.

\section{Resultados obtenidos}

La investigación permitió la incorporación de nuevos elementos en el registro de datos durante la exploración logopédica, que propician un diagnóstico más explicativo y descriptivo; la 
caracterización del lenguaje de los educandos de segundo grado con RDP, con aspectos que proporcionan orientaciones precisas para la atención individualizada al desarrollo de su lenguaje, y la descripción del componente pragmático en la caracterización del lenguaje de los educandos con RDP.

\section{Conclusiones}

La caracterización del lenguaje de los educandos de segundo grado con RDP permitió identificar alteraciones en los componentes fonético-fonológico, léxico-semántico, gramatical y pragmático. Las dificultades en este último se relacionan con el desarrollo de los demás componentes, lo que afecta la comprensión de la intención comunicativa y depende de la integridad del área inductora de la personalidad.

Para el diagnóstico del componente pragmático se sugiere la valoración de la correspondencia entre la intención comunicativa y lo que se comunica, de la participación por turnos en la conversación, del manejo de un código común, de los cambios en la entonación, de las inflexiones y la intensidad de la voz, así como del empleo de conductas afectivas. Así mismo, debe valorarse la coherencia entre los medios verbales y extraverbales: mirada, sonrisa, gestos faciales, mímica, movimientos corporales, el significado de la expresión en el contexto socio-cultural, el lugar y el tiempo donde ocurre el discurso, el ajuste de la comunicación establecida al contexto socio-cultural y a las personas presentes, la relación entre ellas, el carácter de la información, la naturaleza del acto precedente y subsecuente.

Para estimular el desarrollo del componente pragmático se proponen ejercicios en los que puedan manifestar sentimientos mediante las expresiones faciales, interpretar dramatizaciones y emociones, imitar movimientos de animales, realizar pantomimas, diferenciar modulaciones en la entonación, intenciones comunicativas, reconocer o expresar sentimientos, deseos, opiniones, ruegos, describir hechos, personas, acontecimientos, narrar hechos determinados según su suposición y emitir conclusiones 


\section{Referencias}

Cevallos, J. A. (2016). Tratamiento contable de los ingresos de actividades ordinarias procedentes Acuña, X. y Sentis, F. (2004). Desarrollo pragmático en el habla infantil. Revista Onomázein, 10(2), 33-56. Recuperado de http://www.onomazein.net/Artículos/10/2_Acuna.pdf

Álvarez, L., Fernández, L., Ferrer, A., López, M., Sardiñas, A., Castellano, G., y Rojas, A. (2007). Manual de técnicas logofoniátricas. La Habana, Cuba: Editorial Ciencias Médicas. ISBN: 978-959-212-224-6

Cárdenas, C., Martín, M., Méndez, I., y Prado, R. (1979). Los métodos para la exploración logopédica. Ciudad de La Habana: Editorial de Libros para la Educación.

Castellanos, R. M., Betancourt, J. V., Cobas, C. L., Guerra, S., Akudovich, S. A., Borges, S. A., y Conill, J. A. (2013). Fundamentos de Psicología. Texto para estudiantes de las carreras de Educación Especial y Logopedia. Segunda Parte. La Habana, Cuba: Editorial Pueblo y Educación.

Fernández, G. y Huepp, F. (2014). Fundamentos neuropsicológicos del lenguaje. La Habana, Cuba: Editorial Pueblo y Educación.

Fernández, G., Pons, M., Carreras, M. y Rodríguez, X. (2013). Logopedia Segunda Parte. Texto para los estudiantes de las carreras licenciatura en logopedia y educación especial. La Habana, Cuba: Editorial Pueblo y Educación.

Frías, X. (2001). Introducción a la pragmática Revista Philologica Romanica, lanua., 1-35. ISSN: 1616-413X Recuperado de http://www.romaniaminor.net/ianua/ianua/sup.supos.pdf

Guirado, V. C. (2011). Recursos didácticos para la enseñanza-aprendizaje de los escolares con necesidades educativas especiales. Ciudad de La Habana: Editorial Pueblo y Educación.

López, M., López, J. y Villalón, M. (2006). Orientaciones Metodológicas primer grado Tomo 1. Ciudad de La Habana, Cuba: Editorial Pueblo y Educación.

Martínez, F. (2004). Lenguaje Oral. Ciudad de La Habana, Cuba: Editorial Pueblo y Educación.

Monfort, M. (2004). Trastornos del lenguaje. Intervención en niños con trastornos pragmáticos del lenguaje y la comunicación. Revista Neurología 38(1), 85-87. Madrid, España. Recuperado de http://www.dcam.upv.es/ avatel/2Jornada/Monfort.pdf

Torres, M., Domishkievich, S. y Herrera, L. F. (1990) Selección de Lecturas sobre Retardo en el Desarrollo Psíquico. La Habana: Editorial Pueblo y Educación.

Vlasova, T. A, Lubovski, V. I. y Tsipina, N. A. (1992). Niños con retardo en el desarrollo psíquico. La Habana: 


\section{Editorial Pueblo y Educación.}

Vlasova, T. A y Pevzner, M. S. (1981). Niños con Retardo en el Desarrollo. La Habana, Cuba: Editorial de libros para la educación. 
